\title{
The value of accident and emergency based physiotherapy services
}

\author{
C D Morris, S J Hawes
}

\begin{abstract}
Objective-To investigate whether accident and emergency (A\&E) department based physiotherapy has any advantages over its traditional counterpart in providing treatment for soft tissue injuries.

Methods-Two A\&E departments were compared: hospital A had a traditional physiotherapy service, while hospital B had A\&E based physiotherapy. Groups of adult patients from these two hospitals were compared over a one month period. Data on injuries, number of physiotherapy treatment sessions, and outcome were recorded.

Results-There were 27 referrals for physiotherapy in hospital A during the study period $(1 \cdot 17 \%$ of attendances) and 111 referrals in hospital $B(4 \cdot 03 \%)$ $(P<0.001)$.The waiting time for physiotherapy was significantly less at hospital $B$ (3 $v 7 \mathrm{~d}, \mathbf{P}<0.001$ ) despite a far greater number of patients referred. Non-referral at the hospital with the traditional service was due to a perceived long waiting time by the referring doctors. Patients with longer waiting times were found to be less likely to attend their first appointment, and this was therefore more common in the hospital with the traditional service $(39.5 \%$ v 9.8\%).
\end{abstract}

Conclusions-An A\&E based physiotherapy service results in a greater referral rate and a shortened time between referral and first treatment. Further research is needed to evaluate and compare long terms outcomes following treatment by both types of physiotherapy service.

( f Accid Emerg Med 1996;13:111-113)

Key terms: accident and emergency department; physiotherapy; waiting times; referral rate

Traditionally, patients seen in accident and emergency (A\&E) departments who need physiotherapy are referred to a main hospital physiotherapy department which is separate from the $A \& E$ unit. However during the past few years some $A \& E$ units have set up their own physiotherapy services within the department itself in an attempt to improve the service for patients. To date there have been no studies on the possible benefits of such a service. The aim of this study was therefore to compare the "traditional" service with this newer A\&E based service.

\section{Methods}

Two hospital A\&E departments were compared. Hospital A had the traditional physiotherapy service while hospital B had an A\&E based physiotherapy service. They were suitable for comparison as they were part of the same NHS trust, and also employed the same $A \& E$ doctors, who work a shift system between the two hospitals. This helped minimise any bias in referring that might result from individual doctors' treatment regimens or hospital policies. The decision to refer patients for physiotherapy in the two hospitals was left to the discretion of the individual medical staff, within broad guidelines given at the beginning of their post. Each physiotherapy unit has its own staff.

During October 1994 we studied two groups of adult patients who were referred to and discharged from physiotherapy by the $A \& E$ department at the two hospitals. The total number of adult attendances at the $A \& E$ departments was recorded. Patients referred to the physiotherapy department for crutches only were excluded.

For each patient referred, the injury, date referred, and date first seen by a physiotherapist were noted. For patients discharged, the injury, number of treatment sessions and the outcome were noted. From these data the injuries referred, waiting times, average number of treatment sessions, and new patient non-attender (DNA) rates could be found and analysed statistically using the Student $t$ test and the Mann-Whitney U test.

The opinions of referring doctors and physiotherapists relating to the physiotherapy services were also sought using a basic questionnaire.

\section{Results}

At hospital A there were 2311 adult A\&E attendances during the study period. There were 27 referrals for physiotherapy, giving a referral rate of $1.17 \% ; 18.5 \%(5 / 27)$ of the referrals were from the $\mathrm{A} \& \mathrm{E}$ review clinic. During the same period there were 2751 adult A\&E attendances at hospital $\mathrm{B} ; 111$ were referred for physiotherapy, giving a referral rate of $4.03 \%$. Of these $10 \cdot 8 \%(12 / 111)$ were from the $A \& E$ review clinic. This difference between the referral rates for physiotherapy between the two hospitals is statistically significant $(P<0.001)$.

The median waiting time for all referrals was $7 \mathrm{~d}$ (range 1-35) at hospital $\mathrm{A}$, and $3 \mathrm{~d}$ (range 0-14) at hospital $B(P<0.001)$. The data for 
Comparison of waiting times for physiotherapy between the two hospitals

\begin{tabular}{llll}
\hline Injury & $\begin{array}{l}\text { Hospital A } \\
\text { Mean }(95 \% \text { CI })\end{array}$ & $\begin{array}{l}\text { Hospital B } \\
\text { Mean }(95 \% C I)\end{array}$ & Significance \\
\hline Ankle sprain & $9 \cdot 80(5 \cdot 75-13.88)$ & $2.68(2.05-3.67)$ & $\mathrm{P}=0.028$ \\
$\begin{array}{l}\text { Acute neck } \\
\quad \text { sprain }\end{array}$ & $4.82(3.09-6.55)$ & $5.36(4.41-6.31)$ & $\mathrm{P}=0.60$ \\
Knee sprain & $7.83(4.31-11.35)$ & $5.00(3.37-6.63)$ & $\mathrm{NS}$ \\
All others & $6.80(6.06-7.54)$ & $2.52(1.96-3.08)$ & $\mathrm{P}<0.0001$ \\
\hline
\end{tabular}

$\mathrm{CI}$, confidence interval.

these two samples were not normally distributed and therefore the median was found. On considering the injuries separately, the samples were found to be normally distributed, so means were calculated. These data are shown in the table.

During the study period, 38 patients who had originated from $A \& E$ were discharged from physiotherapy at hospital A compared to 155 at hospital B. At hospital A $39 \cdot 5 \%$ of the patients $(15 / 38)$ did not keep their initial appointment or receive subsequent treatment. Of the remainder, $43.5 \%(10 / 23)$ were discharged because of non-attendance at subsequent appointments, with $56 \cdot 5 \%(13 / 23)$ completing their course of physiotherapy. At hospital $\mathrm{B}, 9 \cdot 8 \%$ of the patients (17/155) did not attend their first appointment, $31.9 \%$ (44/138) were discharged because of nonattendance at subsequent appointments, and $68.1 \%$ completed their course of treatment. The difference in these new patient DNA rates was significant $(P=0.007)$, with the long waiting times at hospital A possibly explaining the difference (figs 1 and 2).

No statistical difference was found between the average number of physiotherapy treatment sessions according to injury at the two hospitals.

Of $11 \mathrm{~A} \& \mathrm{E}$ senior house officers, $10 \mathrm{com}$ pleted questionnaires. Nine out of 10 thought it was easier to refer patients for physiotherapy at hospital B. All believed patients would be

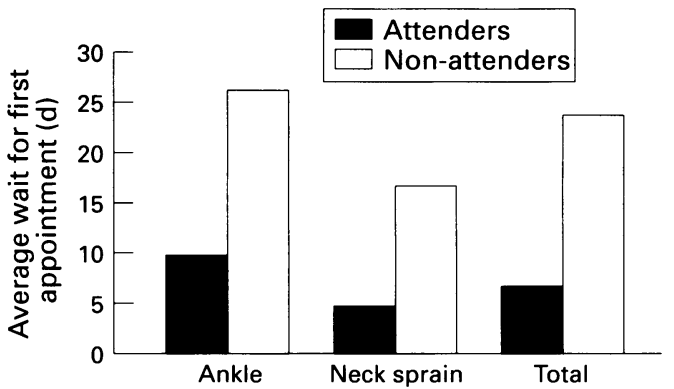

Figure 1 Comparison of waiting times for attenders and non-attenders at hospital $A$

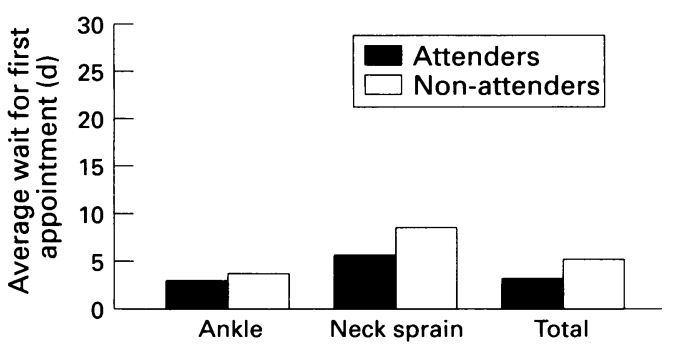

Figure 2 Comparison of waiting times for attenders and non-attenders at hospital $B$ seen more quickly at hospital B and ranked this department as providing the best service. They also stated that a perceived longer waiting time at hospital A deterred them from referring patients at this hospital and that they would refer more patients if physiotherapy services were more readily available.

Questionnaires were completed by the physiotherapists who regularly treated patients referred from A\&E. Seven questionnaires were completed by physiotherapists at hospital A. They felt they did not see enough acute injuries $(5 / 7)$ and that there were inappropriate referrals $(5 / 7)$. They were unsure as to whether $\mathrm{A} \& \mathrm{E}$ based physiotherapy would be of benefit. At hospital B questionnaires were completed by all four physiotherapists working in the $A \& E$ unit. It was believed that the referral rate was of the correct order (4/4), and that the majority of referrals were appropriate (3/4). Both departments stressed the need to avoid patients using the $A \& E$ department to jump the queue for physiotherapy, and it was generally felt that increased communication between $A \& E$ doctors and physiotherapists would improve the service.

\section{Discussion}

Musculoskeletal conditions account for $10-15 \%$ of all time lost from work in the United Kingdom. ${ }^{1}$ Physiotherapy is an important treatment option for these conditions. Anderson $e t \mathrm{al}^{2}$ found that $4.5 \%$ of all patients presenting to a paediatric A\&E department were assessed as needing physiotherapy, but only $1.4 \%$ were actually referred. The most common reason for non-referral was poor availability of physiotherapy services. This finding has been supported by another study, where a $9 \%$ referral rate for physiotherapy in patients with musculoskeletal injuries was found. ${ }^{3}$ Five times this number would have been referred had a physiotherapist made the judgements. Hackett et $a l^{1}$ found that having on-site physiotherapy in a general practice doubled the referral rate and resulted in less time off work for patients.

The referral rate at hospital B was significantly higher than at hospital $\mathrm{A}$ and the average waiting time was significantly shorter. Of the patients referred who attended, the number of treatment sessions was similar at both hospitals. The higher referral rate at hospital $\mathrm{B}$ cannot therefore be accounted for by the referral of less severe injuries. We did not attempt to assess the severity of injury in patients who were not referred or who failed to attend for treatment. The increased referral rate must therefore be due to other factors such as the A\&E doctors views of the services. This was supported by the findings of the questionnaires they completed.

The new patient DNA rate at hospital A was higher than at hospital $\mathrm{B}$. The non-attenders had longer waiting times for treatment, especially at hospital A. The injuries may have improved considerably before the appointment date and this could explain why some of these patients failed to attend their initial appointments. It could be argued that if patients can 
recover without physiotherapy then they do not need it. However, there is little argument that physiotherapy is particularly beneficial for certain soft tissue injuries. Rutherford et $\mathrm{al}^{4}$ showed this when they found that the strength and size of quadriceps musculature was decreased in acutely injured legs when compared to the uninjured leg, and that these measurements can be returned almost to normal after a sufficient training schedule. These results suggest that physiotherapy is needed in the immediate postinjury period. It has also been found that active treatment in whiplash injuries resulted in greater improvements in pain and cervical movement when compared with rest alone. ${ }^{5}$ Work on the treatment of sprains and partial tears of the lateral ligament of the ankle has yielded similar results. ${ }^{6}{\text { Pickard et } a l^{8}}^{8}$ studied the influence of immediate physiotherapy in the management of acute knee injuries. They found that referral after a period of rest and review was the most cost-effective treatment policy. Interestingly they also found that $20.5 \%(8 / 39)$ of the group not treated with physiotherapy were later investigated for suspected meniscal injury, compared to $3 \cdot 1 \%$ (1/32) of the group treated with immediate physiotherapy.

If the option of employing a full time physiotherapist in the $A \& E$ department proved to be impractical, it would be important for the $A \& E$ senior house officers to receive tutorials from the physiotherapists during their induction training, when the new doctors would learn which injuries would benefit from physiotherapy and how the service in their hospital operates. Hackett et $a l^{1}$ found that patients who had direct access to physiotherapy had fewer prescriptions for drugs such as nonsteroidal anti-inflammatory agents compared with patients with no direct access to physiotherapy. This reduction in prescribing costs may help to offset any possible financial implications of employing an $A \& E$ physiotherapist.

Our study shows that having a physiotherapy service based within the $A \& E$ department results in an increased number of patients treated with physiotherapy, and decreased waiting times, with more patients attending their initial appointments. It is also preferred by the referring medical staff. Further research into length of disability and time off work needs to be done to determine whether early physiotherapy improves the patients' long term outcomes. The impact of readily available physiotherapy on the number of late referrals, when injuries have become chronic, also needs to be assessed.

1 Hackett GI, Bundred P, Hutton JL, O'Brien J, Stanley IM. Management of joint and soft tissue injuries in three general practices: value of on-site physiotherapy. $\mathrm{Br} \mathcal{F}$ Gen Pract 1993;43:61-4.

2 Anderson DM, Blackwell RG, Tilley KC, Cockington RC [letter]. Use of physiotherapy in a children's casualty department. Med f Aust 1982;1:203.

3 Jones GAC. Musculoskeletal problems at an accident \& emergency department, and in general practice. NZ Med f 1983;96:529-31.

4 Rutherford OM, Jones DA, Round JM. Long lasting unilateral muscle wasting and weakness following injury and immobilisation. Scand $\mathcal{F}$ Rehab Med 1990;22:33-7.

5 Mealy K, Brennan H, Penelon GCC. Early mobilisation of acute whiplash injuries. $B M \mathcal{F} 1986 ; 292: 656-7$.

6 Brooks SC, Potter BT, Rainey JB. Treatment for partial tears of the lateral ligament of the ankle. $B M \mathcal{F}^{1981 \text {; }}$ 282:606-7.

7 Leaman AM, Simpson DE. Treatment of sprained ankles by physiotherapists at professional soccer clubs. Arch by physiotherapists at p
Emerg Med 1988;5:177-9.

8 Pickard MAD, Venner RM, Ford I, Todd BD. Influence of immediate physiotherapy in the outpatient management of acute knee injuries: a controlled study. Arch Emerg Med 1990;7:249-52. 